\title{
Malaria outbreak response in urban Santo Domingo, Dominican Republic: lessons learned for community engagement
}

\author{
Dianelba Valdez' ${ }^{1}$, Hunter Keys ${ }^{2,3}$ Keyla Ureña ${ }^{1}$, Domingo Cabral', Francisco Camilo ${ }^{1}$, \\ Eulalia C. Ogando4, Luz Mercedes 5 , Gregory S. Noland², Stephen B. Blount ${ }^{2}$, James V. Lavery , \\ Luccene Desir, ${ }^{7}$ Jose Puello ${ }^{1}$
}

Suggested citation Valdez D, Keys H, Ureña K, Cabral D, Camilo F, Ogando EC, et al. Malaria outbreak response in urban Santo Domingo, Dominican Republic: lessons learned for community engagement. Rev Panam Salud Publica. 2020;44:e92 https://doi.org/10.26633/ RPSP.2020.92

ABSTRACT

\begin{abstract}
Community engagement is crucial for public health initiatives, yet it remains an under-studied process within national disease elimination programs. This report shares key lessons learned for community engagement practices during a malaria outbreak response in the Los Tres Brazos neighborhood of urban Santo Domingo, Dominican Republic from 2015-2016. In this two-year period, 233 cases of malaria were reported-more than seven times the number of cases (31) reported in the previous two years. The initial outbreak response by the national malaria program emphasized "top-down" interventions such as active surveillance, vector control, and educative talks within the community. Despite a transient reduction in reported cases in mid-2015, transmission resurged at the end of 2015 . The program responded by introducing active roles for trained community members that included door-to-door fever screening, testing with rapid diagnostic tests and treatment. Malaria cases declined significantly throughout 2016 and community-based active surveillance infrastructure helped to detect and limit a small episode of transmission in 2017. Results from qualitative research among community members revealed two key factors that facilitated their cooperation with community-based surveillance activities: motivation to help one's community; and trust among stakeholders (community health workers, their neighbors and other key figures in the community, and malaria program staff and leadership). This experience suggests that community-led interventions and the program's willingness to learn and adapt under changing circumstances can help control malaria transmission and pave the way for elimination.
\end{abstract}

Keywords Malaria; community-institutional relations; community participation; disease elimination; Dominican Republic.

The island of Hispaniola, shared between the Dominican Republic (population, 10.3 million) and Haiti (population, 10.8 million), is the last remaining malaria-endemic island in the Caribbean. Both countries have committed to malaria elimination (1). The burden of disease is much lower in the
Dominican Republic, with 398 reported cases in 2017-only $2 \%$ of the 19,533 malaria cases reported island-wide (2). All locally acquired cases on Hispaniola are Plasmodium falciparum, which remains chloroquine-sensitive and is transmitted by Anopheles albimanus mosquitoes. Transmission occurs year-round with

\footnotetext{
1 Centro de Prevención y Control de Enfermedades Transmitidas por Vectores y Zoonosis, Santo Domingo, Dominican Republic

2 The Carter Center, Atlanta, United States of America. $\triangle$ huntkeys@gmail.com

3 Department of Anthropology, University of Amsterdam, Amsterdam, the Netherlands

4 Junta de Vecinos, Los Tres Brazos, Santo Domingo, Dominican Republic
} 
seasonal peaks typically observed in June and in NovemberDecember.

Malaria elimination depends on community participation in interventions, including passive and active surveillance, mosquito habitat reduction, and enacting preventative behaviors (3). To contribute to an evidence base for successful community engagement in public health programs $(3,4)$, this report shares key lessons from a malaria outbreak response in urban Santo Domingo, the capital of the Dominican Republic, from 2015-2016.

\section{MALARIA OUTBREAK IN SANTO DOMINGO}

Historically, malaria in the Dominican Republic was a rural disease, with transmission occurring predominantly in agricultural regions and along the border with Haiti (5). Cases occurred in Santo Domingo, but in low numbers. For example, the metropolitan area-comprised of the Santo Domingo East, West, and North municipalities and the Distrito Nacional-reported no more than 65 cases annually (less than $7 \%$ of all cases nationally) between 2011-2013. However, in early 2014 reported cases surged in Santo Domingo resulting in a five-fold annual increase from 40 cases in 2013 to 214 cases in 2014. Causative factors leading to the outbreak remain unknown but may relate to migration into the city from outlying, endemic areas or intra-urban population movement into and out of malaria transmission zones. Since 2015, metro Santo Domingo has accounted for $51-78 \%$ of cases nationally-due to both sustained transmission in Santo Domingo and reduction in transmission in other parts of the country.

An initial focus of the Santo Domingo outbreak was Los Tres Brazos neighborhood, a low-lying, impoverished area in the East municipality lying at the convergence of the Ozama and Isabela rivers. Los Tres Brazos (population 63 000) has an average population density of 18500 persons $/ \mathrm{km}^{2}$ and is replete with stagnant canals, thick vegetation (riverine plants known as lilas), and inadequate sanitation and physical infrastructure. There are two publicly-funded primary care units and one hospital in the area. Poor socioeconomic conditions force many residents to search for informal work elsewhere in the city. Thus, malaria transmission in the area results from a complex interplay of biological and social factors: Plasmodium parasites, a susceptible human population, a favorable environment for mosquito vectors, poverty, economic migration and high human mobility, and limited healthcare resources.

In 2013 and 2014, only 12 and 19 malaria cases were reported in the Los Tres Brazos neighborhood, respectively, out of approximately 2000 samples tested each year. Seven cases were reported in the last eight weeks of 2014, suggesting the start of sustained transmission. As shown in Figure 1, transmission increased significantly in early 2015, with 60 cases reported by late May, compared to only 5 cases over the same 20-week period in 2014. In total, 162 confirmed cases were reported in 2015 from 10707 samples tested, with weekly incidence peaking at 16 cases in the final week of the year. High rates of testing continued into 2016, including the launch of active surveillance by community members (comunitarios), as detailed in the following section. Cases declined steadily throughout 2016, with only 71 cases-the vast majority occurring in the first half of the year-identified among the 8352 samples tested. A minor resurgence was detected from mid-2017 to early 2018, but incidence never surpassed more than 4 cases per week. Only 4 cases were reported in all of 2018.

While this suggests sustained control of malaria transmission in the Los Tres Brazos neighborhood, the area is currently experiencing another severe outbreak in 2019-2020. It is unclear whether this is the result of transmission resurgence or newly imported cases into the area. In the initial phase of transmission, case investigation determined that none of the confirmed

${ }^{1}$ FIGURE1. Weekly malaria incidence and timeline of community-based interventions, Los Tres Brazos neighborhood, Santo Domingo, Dominican Republic, 2013-2018. A. Forums with community members and leaders (November 2014); B. Recruitment of community members for vector control activities (January 2015); C. Indoor residual spraying; mosquito net distribution campaigns (January-April 2015); D. Indoor and outdoor residual spraying (January-September 2015); E. Deployment of comunitarios for active surveillance (November 2015-January 2016); F. Additional training and accompaniment of comunitarios; ongoing active surveillance (January 2016-July, 2016).

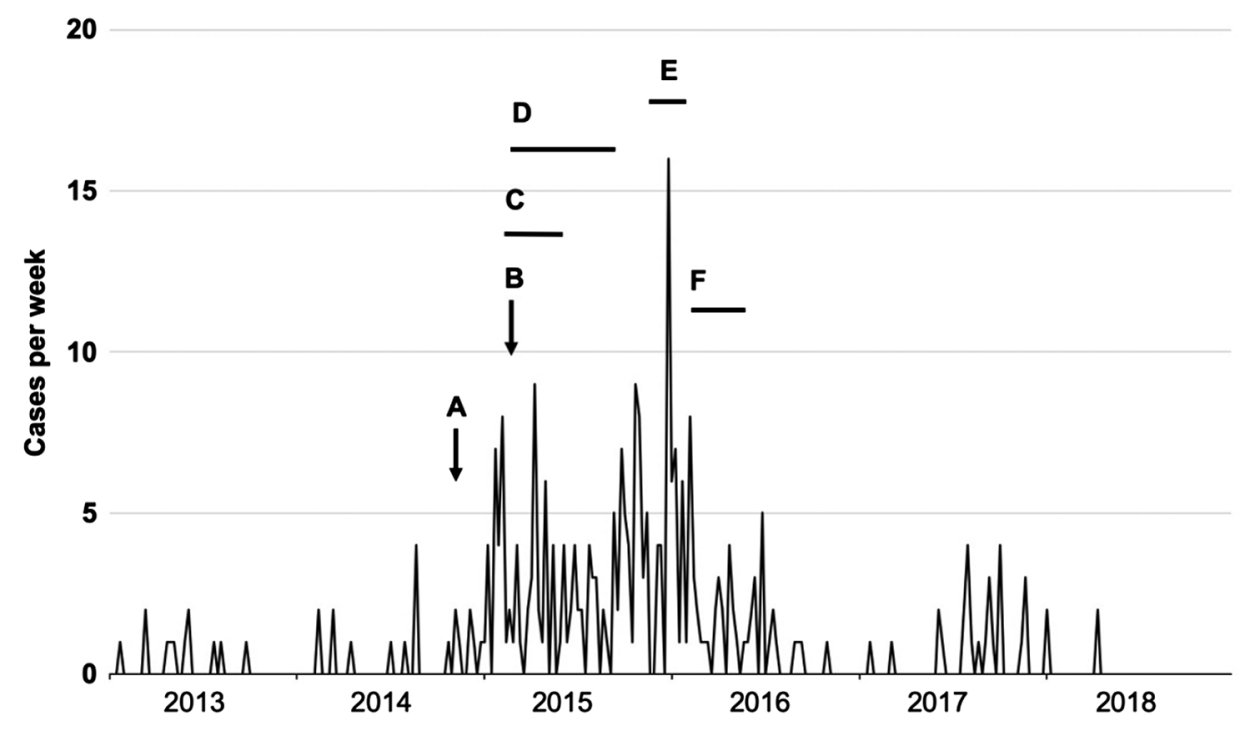

' Figure prepared by the authors based on unpublished data at CENCET. 
malaria cases in 2015-2018 reported travel outside of Los Tres Brazos in the preceding 3 months, with the exception of a Venezuelan immigrant with $P$. vivax in 2017.

At the time of the outbreak in late 2014, standard antimalaria interventions in the Dominican Republic followed the National Strategic Plan for Malaria (2008-2012). These included nationwide health facility-based surveillance and reporting, risk stratification, and prompt diagnosis (using microscopy as the gold standard) and treatment (with chloroquine plus primaquine first-line treatment for uncomplicated P. falciparum). In high-risk areas, additional strategies were recommended such as long-lasting insecticide treated net (LLIN) distribution, indoor residual spraying (IRS), and active surveillance measures, including both door-to-door and campaign-style fever screening, testing using rapid diagnostic tests (RDTs), and treatment.

Anti-malaria interventions across the country are coordinated by the Center for Prevention and Control of Vector-borne and Zoonotic Diseases (Spanish acronym, CECOVEZ), an agency of the Dominican Ministry of Health. The agency's Spanish acronym at the time of the 2015-2016 Los Tres Brazos outbreak, CENCET, will be used here. As a descendent of the National Malaria Eradication Service, CENCET retained a vertical program orientation in which CENCET malaria program technicians conducted the bulk of interventions across the country. This included CENCET's initial response to the Los Tres Brazos outbreak. As discussed below, these strategies evolved over time in both content and context. Community engagement evolved from "top-down" strategies to a more "bottom-up" approach, in which community members were recruited and trained to assist in surveillance and treatment. This shift in engagement strategies took place against a backdrop of expansion in the number and severity of malaria outbreaks sites in Santo Domingo, transmission of other vector-borne diseases, including dengue and Zika viruses, and decentralization of the country's malaria program.

\section{THE RESPONSE: RETHINKING AND IMPLEMENTING COMMUNITY ENGAGEMENT STRATEGIES}

Consistent with its vertical program structure, CENCET conducted regular malaria surveillance and vector-control activities in at-risk areas of Santo Domingo prior to the 20152016 outbreak. For example, active surveillance by CENCET field staff accounted for $92 \%$ of the samples tested for malaria in Los Tres Brazos in 2013 and 2014. In the community, CENCET field staff were known colloquially as la gente de malaria (the malaria people). When sustained transmission first appeared in late 2014, CENCET began holding community forums to raise awareness about malaria and encourage reporting of fever (Figure 1, A). Pre-existing relationships between CENCET and community leaders at juntas de vecinos (neighborhood associations) greatly facilitated these meetings (6). However, increasing incidence into early 2015 compelled CENCET to establish more direct lines of communication with community residents to facilitate the identification, reporting, and follow up of fever cases. As the outbreak continued, CENCET identified more active roles for community members for vector control activities, such as mosquito breeding site identification, IRS of 1381 homes, and distribution of more than 3000 LLINs in Los Tres Brazos between January-April 2015 (Figure 1, B-C). Despite a five-fold increase in active surveillance (from 1689 samples collected in 2014 to 10196 in 2015), the continued increase in cases in late 2015 indicated that a novel approach was needed. A key limitation for surveillance was the unpredictable work schedules of many neighborhood residents that made it difficult for CENCET staff to screen and test individuals outside of 'normal working hours'. This led to the idea of recruiting community members to conduct active surveillance themselves.

Beginning in November 2015, CENCET worked with neighborhood associations, local non-governmental organizations (NGOs), and churches in Los Tres Brazos to recruit a cadre of community members called comunitarios (community health workers), to perform active surveillance for malaria (Figure 1, E-F). Collaboration with these local institutions was critical not only for identifying and recruiting comunitarios but to lay the groundwork for long-term, sustained involvement of residents and community leaders. These key figures were also consulted regularly to assess perceptions of the community, such as people's receptivity to comunitarios.

CENCET trained and supervised an initial group of 20 candidates. Eventually, a core group of 14 comunitarios conducted door-to-door fever-screening in their sub-barrios for approximately four hours each day (between late-afternoon and nighttime) starting in January 2016. Each comunitario received a small stipend. Anyone with suspected fever was tested for malaria by point-of-care RDT, followed by thick and thin blood films for confirmatory microscopic diagnosis. RDTpositive individuals were offered treatment by comunitarios. RDT-negative individuals were encouraged to seek care for their fever from a local health care provider. Program leadership set a goal of approximately 20 RDTs per day for each comunitario to achieve high-coverage surveillance. In 2016, the comunitarios made 32760 home visits and detected $41 \%$ of the 39 cases diagnosed through active surveillance in the Los Tres Brazos neighborhood. In 2017, they visited 34560 households and detected $81 \%$ of the 26 active surveillance cases. Importantly, candidates not selected for active surveillance teams but showing strong motivation were integrated into other community-based activities like vector-control.

The Los Tres Brazos malaria outbreak occurred against a backdrop of two key contextual events. First, the Dominican government initiated a major decentralization of the national malaria program in December, 2014. This shifted primary responsibility for malaria program implementation from CENCET to local health districts, which absorbed a new set of administrative and technical challenges. The second event was the 2015-2016 Zika virus epidemic in the Americas. Zika virus, transmitted predominantly by Aedes aegypti mosquitoes, was first reported in the Dominican Republic in January, 2016. Cases increased through 2016, with a peak in March and April, 2016. A total of 5226 Zika virus cases were reported nationally in 2016, including 753 cases in the East municipality of Santo Domingo. The high-profile risk of microcephaly and other fetal abnormalities associated with Zika infection during pregnancy likely heightened awareness of vector-borne diseases generally and may have increased receptivity to vector control measures in susceptible locations like Los Tres Brazos.

\section{METHODS}

To better understand rationales, motivations, and challenges to community engagement during this malaria outbreak, five 
in-depth interviews, three focus groups, and multiple informal conversations were held with CENCET executive and field staff and Los Tres Brazos comunitarios from 2017 into 2019. Additionally, one co-author (HK) spent a total of six months in Santo Domingo from 2018-2019 accompanying malaria field teams and collecting personal observations and field notes to help triangulate data and follow-up key findings as needed.

Interviews and focus groups sought to capture local (emic) perspectives and explanations for community engagement during the malaria outbreak response. Data collection was facilitated through longstanding relationships among all co-authors and key figures in Los Tres Brazos. Interviews and focus groups were audio-recorded and transcribed verbatim into the original Spanish. These transcripts were analyzed alongside field notes using grounded theory, which builds a general theoretical explanation from commonly found themes in the data (7). The findings described here are part of a larger ethnographic study of malaria and community engagement that was approved by the Dominican Consejo Nacional de Bioética en Salud (CONABIOS) and the Ethical Review Board of the University of Amsterdam, and declared exempt from review by Emory University Institutional Review Board. All participants gave verbal informed consent. No personally-identifying information was recorded in final transcripts or field notes.

\section{RESULTS}

Certain defining elements characterized the motivations of comunitarios, including a spirit of service, the desire to maintain trust with neighbors, and the perspective that their role as comunitarios was una vocación, or calling, rather than a typical job to make money. For example, a middle-aged comunitario in Los Tres Brazos said "I feel good when there is someone with a problem and I can help resolve [it], if it's malaria [...] I feel as though I rise to heaven when I resolve this problem; I don't know why, but I feel good." Another comunitario underscored the importance of teamwork, saying that, "If there is no team, there is nothing, nothing, because alone, I cannot do anything." These remarks reflect the collective sense of ánimo (energy, intent, or motivation) that comunitarios and others shared as they worked together to bring the outbreak under control.

In their regular lives, comunitarios considered themselves todólogos, or jacks-of-all-trades, doing their best to find whatever work they could. Economic hardship is a pervasive feature of life in Los Tres Brazos. The need to support one's family could have led some comunitarios to search for more lucrative sources of income elsewhere or even sap their motivation. Instead, they considered checking in on their neighbors as una vocación, or a calling. Put simply, working within the malaria program was a way to mejorar la vida, or improve life's circumstances, for themselves and others.

Fulfilling their roles as comunitarios could only come about through la confianza (trust) with fellow community members. To accomplish their work, comunitarios needed to enter people's homes, explain the purpose of blood testing, and notify CENCET of any positive cases. While infrequent, some people invariably declined blood testing. One comunitario shared her way of encouraging someone who refused RDT: "I try to convince them, saying, 'My dear, it is for your health; you know that there are many tropical diseases and we're trying to get rid of them, and if you have it, it will spread.'" For their part, the comunitarios never turned anyone away who requested a test, regardless of clinical history or presentation. In one anecdote, a comunitario said that even young children still run up to her in the street, perfectly healthy and smiling, and hold out their fingertips, wanting their blood tested. Trust was also evident in the late-night phone call from a febrile neighbor who requested an RDT, which fortunately was negative.

At the same time, it was necessary to foster trust between CENCET and the comunitarios. To avoid an overly patronizing dynamic, CENCET staff assumed a respectful and deferential attitude that was embodied in an oft-repeated, rhetorical question that one key figure within CENCET would ask community members at meetings: "After those of us with CENCET leave the area today, who's still around?" The question was initially met with befuddled looks, but once the answer became clearthat they, the comunitarios and their neighbors would still be present-they realized their crucial role: they, as community residents, knew better about who in the barrio was sick and in need of testing rather than the technical experts at CENCET.

Notably, residents seemed to trust comunitarios even more than medical professionals. This arose out of instances in which healthcare providers incorrectly diagnosed patients with viral syndromes or dengue, rather than malaria. Appropriate diagnosis and treatment came about only after the patient had returned home, fallen more ill, and was visited by a comunitario. Some comunitarios noted that previous experiences with misdiagnosis even kept some people from consenting to RDT testing. Having been told by medical professionals that their illness was "only dengue" or "a common cold," some people were hesitant to have their blood tested once back in the community. In response, one comunitario told such individuals that, "[But] you still have fever, and you came from the doctor; we [still] have to do this test to see what's going on with you."

A final theme was that care was bidirectional: comunitarios cared for their communities, but the communities also cared for them. Certain parts of Los Tres Brazos are notoriously dangerous, particularly at night. Consequently, to do their work, comunitarios worked with key, local figures, including gang leaders and drug dealers, who personally escorted them through some neighborhoods. Trust, therefore, was integral to all relationships comprising the malaria response: between CENCET staff and trained comunitarios; between comunitarios and neighbors; and between comunitarios and certain figures in Los Tres Brazos who might have otherwise been held with suspicion, trepidation, or in low regard.

\section{DISCUSSION}

The 2015-2016 malaria outbreak in Los Tres Brazos neighborhood presented formidable challenges: the concentration of cases in densely populated, hard-to-reach areas; irregular work schedules of neighborhood residents; the co-occurrence of other vector-borne diseases; and the implementation of a new decentralization policy. While CENCET has long maintained a presence in this area, the outbreak called for new approaches to community engagement, notably sharing responsibilities for vector control and case detection with trained community members. Evidence suggests that the malaria outbreak continued unabated until the comunitarios were deployed to conduct active surveillance within the Los Tres Brazos neighborhood, diagnosing and treating any suspected malaria cases. 
There are limitations to this study. While the results suggest an association with scale-up of comunitarios and subsequent reduced malaria incidence, ascribing direct, or sole, causation is difficult. For example, the impact of other, concurrent interventions (LLIN, IRS) cannot be assessed because no evaluative data were collected to compare against the work of comunitarios. Another is the concurrent presence of high-profile mosquito-borne diseases (Zika, dengue) that may have led the population to take more precautions.

Based on this experience, we recommend that malaria programs: 1. identify and work collaboratively with local institutions, organizations, and community figures and consider ways to provide more equal footing for them, such as through community advisory boards (8); 2 . maintain a willingness to learn and adapt based on changing circumstances; 3 . acknowledge that social networks are one of the strongest assets of malaria-affected communities; and 4. ensure that technical expertise and supply chains are coordinated by a centralized, public health authority during outbreaks. It must be recalled that community engagement with comunitarios took place when the malaria program was still centralized; after decentralization, training and supervision of comunitarios now fall under the purview of local health district offices in Los Tres Brazos, with CENCET playing a supporting role. This continues to pose unique challenges going forward with the rise in cases from 2019 into 2020.

These lessons are relevant for other malaria-prone areas of Santo Domingo, as well as other public health campaigns. This includes the current COVID-19 pandemic, with WHO recommending utilization of community health workers for COVID-19 response activities given their trusted status within communities (9). In the context of rapid global change, shifting transmission dynamics of vector-borne diseases like malaria and the emergence of novel infectious diseases like COVID-19 underscore the importance of building community resilience and strengthening health systems (10). Consequently, there is urgent need for additional studies like this to continue generating evidence for community engagement practices (11). Finally, while not discussed here, it is important to coordinate with local health providers to ensure availability of diagnostics and treatment for malaria and to promote sustainable healthseeking behavior.

In sum, true community experts are the people living there. Working collaboratively with affected communities for malaria control and elimination entails a social process of dialogue, trust, and mutual support.

Author contributions. DV, HK, KU, GN, SB, JL, and LD conceived the study design, collected and analyzed data, interpreted the results, and reviewed the paper. DV drafted the initial manuscript. HK, KU, and GN completed subsequent revisions. DC, FC, and $\mathrm{EO}$ contributed to the study design, facilitated data collection, and interpreted findings. LM and JP provided leadership and supervisory roles during the outbreak response. All authors reviewed and approved the final version.

Acknowledgments. The authors gratefully acknowledge the hard work and perseverance of the comunitarios. The authors thank the reviewers who provided helpful comments on an earlier version of this manuscript.

\section{Conflicts of interest. None declared.}

Financial support. Not applicable.

Disclaimer. Authors hold sole responsibility for the views expressed in the manuscript, which may not necessarily reflect the opinion or policy of the RPSP/PAJPH and/or PAHO.

\section{REFERENCES}

1. World Health Organization (WHO). Meeting of the International Task Force for Disease Eradication-November 2012. Wkly Epidemiol Rec. 2013;88:75-80.

2. World Health Organization. World Malaria Report. Geneva: WHO; 2018.

3. Whittaker M, Smith C. Reimagining malaria: five reasons to strengthen community engagement in the lead up to malaria elimination. Malar J. 2015;14:410.

4. Lavery JV. Building an evidence base for stakeholder engagement. Science. 2018;361(6402):554-6.

5. World Health Organization (WHO). Meeting of the International Task Force for Disease Eradication - 12 May 2006. Wkly Epidemiol Rec. 2007:82(4):25-32.

6. Gonzales M, Baker MC, Celestino A, Santa Morillo D, Chambliss A, Adams S, et al. How lymphatic filariasis was eliminated from an urban poor setting in Santo Domingo, Dominican Republic. Int Health. 2019;11(2):108-18.

7. Glaser B, Strauss A. The discovery of grounded theory: strategies for qualitative research. Chicago, IL: Aldine; 1967.

8. Quinn S. Protecting human subjects: the role of community advisory boards. AJPH. 2004;94(6):918-22.
9. WHO, UNICEF. Community-based health care, including outreach and campaigns, in the context of the COVID-19 pandemic, Interim guidance: WHO/UNICEF; 2020. Available from: https:// www.unicef.org/media/68811/file/Guidance-Community-basedHealth-Care.pdf.

10. Bardosh K, Ryan S, Ebi K, Welburn S, Singer B. Addressing vulnerability, building resilience: community-based adaptation to vector-borne diseases in the context of global change. Infect Dis Poverty. 2017;6(1):166.

11. Atkinson J-A, Vallely A, Fitzgerald L, Whittaker M, Tanner M. The architecture and effect of participation: a systematic review of community participation for communicable disease control and elimination. Implications for malaria elimination. Malar J. 2011;10(225):1-33.

Manuscript received on 25 March 2020. Revised version accepted for publication on 25 June 2020. 


\section{Respuesta al brote de malaria en la zona urbana de Santo Domingo, República Dominicana: lecciones aprendidas sobre la participación de la comunidad}

RESUMEN La participación de la comunidad es crucial para las iniciativas de salud pública, pero sigue siendo un proceso poco estudiado dentro de los programas nacionales de eliminación de enfermedades. En este informe se presentan las principales lecciones aprendidas respecto de las prácticas de participación comunitaria durante la respuesta al brote de malaria en el barrio Los Tres Brazos de la zona urbana de Santo Domingo, República Dominicana, de 2015 a 2016. En este período de dos años se notificaron 233 casos de malaria, más de siete veces el número de casos (31) notificados en los dos años anteriores. La respuesta inicial al brote por parte del programa nacional de malaria hizo hincapié en intervenciones "de arriba abajo" como la vigilancia activa, el control de vectores y las charlas educativas dentro de la comunidad. A pesar de la reducción transitoria de los casos notificados hacia mediados de 2015, la transmisión resurgió a finales de ese año. El programa respondió introduciendo funciones activas para miembros de la comunidad capacitados que incluían la detección de fiebre de casa en casa, pruebas de diagnóstico rápido y tratamiento. Los casos de malaria disminuyeron significativamente durante 2016 y la infraestructura de vigilancia activa basada en la comunidad ayudó a detectar y contener un episodio pequeño de transmisión en 2017. Los resultados de la investigación cualitativa entre los miembros de la comunidad revelaron dos factores clave que facilitaron su cooperación con las actividades de vigilancia basadas en la comunidad: la motivación para ayudar a la propia comunidad y la confianza entre las partes interesadas (los trabajadores sanitarios de la comunidad, los vecinos y otros actores clave de la comunidad, y el personal y la dirección del programa de lucha contra la malaria). Esta experiencia indica que las intervenciones dirigidas por la comunidad y la voluntad del programa de aprender y adaptarse a las circunstancias cambiantes pueden ayudar a controlar la transmisión de la malaria y facilitar el camino para su eliminación.

Palabras clave Malaria; relaciones comunidad-institución; participación de la comunidad; erradicación de la enfermedad; República Dominicana. 